\title{
Incorporating learning technologies into undergraduate radiography education
}

J.Lorimer \& A. Hilliard

Introduction

A number of challenges face today's lecturer. Widening access brings increasing diversity to the student group. Students now have different priorities and lifestyles when compared to the traditional $v^{1} w^{1,2}$. With these changes, lecturers need to recognise that teaching should be realigned to meet the students' needs ${ }^{3,4}$.

This study was based on changes made to a second year undergraduate module forming part of a BSc (Hons) Diagnostic Radiography and Imaging programme. The module had previously been taught during two two-hour lecture type sessions delivered in the morning and afternoon of the same day. Lectures were being delivered to large groups; teaching accommodation was not always optimal and attendance was inconsistent. The authors found student focus and attention levels were variable, and periods of background noise exacerbated difficulties. It was felt that this format of teaching could be updated and improved. Many writers have taken issue with the use of lectures. Laurillard ${ }^{5}$ has said that perhaps lectures were defensible in the old university systems of selection of students on the basis of standardized entrance examinations. Today the more open access and modular courses make it unlikely that a class of students will be sufficiently similar in background and capabilities to make lectures workable as a principal teaching method. This suggestion matches the researchers' experience. Despite the advent of readily available electronic means of delivery, lecturing is still seen by many as the most cost-effective means of delivering content in higher education ${ }^{6}$.

It was felt, following research, that the integration of learning technologies would be an effective method of overcoming the stated difficulties. Contrary to the notion that education technology encourages campus based institutions to deliver more of their provision at a distance, research literature suggests that educational technology can have the effect of drawing staff and students closer together, both physically and virtually ${ }^{7,8}$. The authors felt it was important to maintain cohesion within the module and to maintain good communication and dialogue between students and staff. 
Considering available literature, the module leader made the decision to reduce the number and frequency of lectures, in favour of podcasts/audio downloads ${ }^{3}$. The idea of making a digital voice recording of the material to be taught (with accompanying PowerPoint ${ }^{\mathrm{TM}}$ slides) available to the students would offer a degree of flexibility for students to access material at a time and place convenient to themselves ${ }^{3}$. It was recognised that there would still have to be opportunities for dialogue between the lecturer and the students. With this in mind, the electronic learning materials were supplemented by regular small group seminars.

There is a paucity of literature on the use of blended learning technologies in the field of medical radiation sciences. The authors believe that the existence of a Blended Learning Unit in their institution, in tandem with increasing cohort size in radiography, are the driving forces behind the incorporation of the discussed innovations into the radiography curriculum.

The aim of the project was to create a blended learning module, which allowed some flexibility of learning location and time, and increased classroom interactivity to enhance student learning and understanding of the topics taught. Blended learning is defined as "educational provision where high quality e-learning opportunities and excellent campus-based learning are combined or blended in coherent, reflective and innovative ways so that learning is enhanced and choice is increased"9.

\section{Method}

\section{Changes in module design}

The changes in the module design were introduced into the module at the start of the 2006/2007 academic year and are illustrated in figures 1 , below. The module had previously been taught weekly by a 2 hour lecture in the morning, followed by a 2 hour lecture in the afternoon. The weekly morning lecture was removed, and the lecture content to introduce topic areas were developed to be delivered electronically via the University's managed learning environment (MLE) as PowerPoint ${ }^{\mathrm{TM}}$ presentations which were accompanied by audio download files. These could also be accessed as stand alone podcasts. The weekly afternoon lecture was changed to small group work seminars, which were designed to build on the information delivered by the podcast and PowerPoint ${ }^{\mathrm{TM}}$ presentation (see figure 1). During the 2 hour small group seminars, students rotated between 4 
planned activities designed to enhance and reinforce their prior learning. One of the activities was a multiple choice session using an electronic voting system (EVS). The purpose of this was to assess the students understanding of the topic area, enabling instant feedback on any misconceptions ${ }^{10}$. It was also used to prepare the students for assessment of the module, one element of which is a multiple choice examination. The use of EVS as a tool to support exam preparation has been documented, it was thought to be particularly suited to the needs of the student with regard to the method of summative assessment ${ }^{11}$.

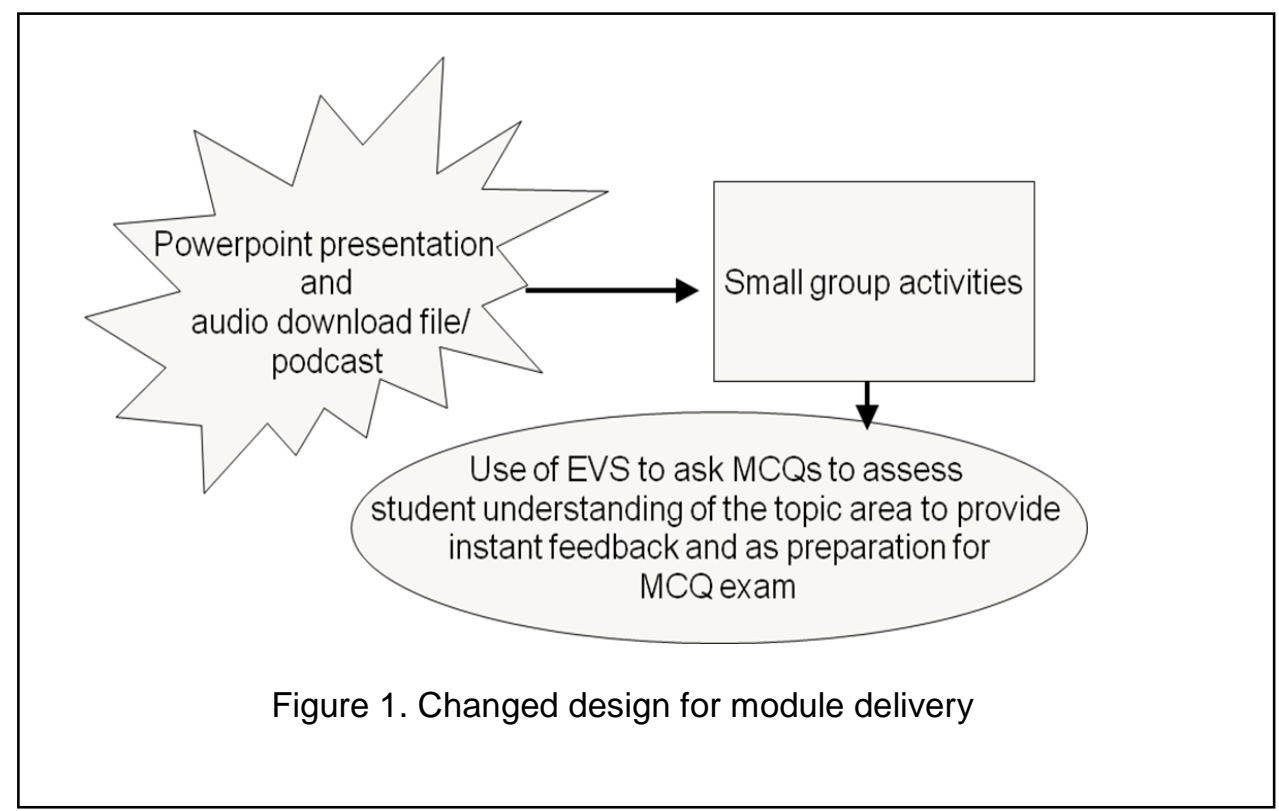

The podcasts and presentations were made available to the students a week in advance of the small group seminars. This was to give students the opportunity to access and use the resources at a time and place convenient to themselves ${ }^{3,12}$.

Podcasting may be viewed as personalised on-demand multi-media content that is distributed to a subscriber's computer via the Real Simple Syndication (RSS) protocol ${ }^{13}$. The audio download files were recorded using a digital voice recorder (DVR) which was capable of recording directly as an mp3 file format. Both the audio download file/podcast and accompanying PowerPoint ${ }^{\mathrm{TM}}$ presentation were divided into 'chunks' generally lasting between twenty to thirty minutes. This allowed to students to "take a break" and review challenging topic areas. 
On completion of recording the audio file, the DVR was connected to a computer and saved as an mp3 file. It was then easy to upload the mp3 file to the module website as a podcast, linking it to the prepared PowerPoint ${ }^{\mathrm{TM}}$ presentation. Educause ${ }^{14}$ suggests that podcasting broadens educational options in a non-threatening and easily accessible manner because students are already familiar with the underlying technology.

An EVS typically comprises four primary elements: a tool for presenting lecture content and questions (e.g. a computer, PowerPoint ${ }^{\mathrm{TM}}$ and a digital projector), electronic handsets that enable students to respond to a lecturer's questions, receivers that capture students' individual responses and software that collates and presents students' responses. The use of EVS has been reported as becoming more widespread in higher education ${ }^{10}$.

\section{Method of evaluation}

The sample size was 102 students. The student group was diverse in terms of geographical location, ethnic origin, background and age. $35 \%$ of the student group were mature students, over the age of 21 years old on admission to the programme.

The degree of engagement with technology in everyday life has prompted authors to state that computers and attendant technology should be essential rather than desirable adjuncts to education ${ }^{15}$. In introducing learning technologies into the module design, the researchers were mindful of the possibility that mature students might feel disadvantaged because of their more traditional experiences of education, and they may not be as comfortable accessing and using learning technologies. It is recognised that the use of technologies is not confined to younger learners, and many mature students are confident with a variety of technologies. Despite this the authors felt it important that in introducing learning technologies into the module design no students were made to feel disadvantaged by their lack of familiarity with technology. Comparisons between students entering straight from school or college (direct entry), and mature students were built into the end of module evaluation. 
The study used a quantitative paradigm, and a survey was conducted to collect perceptions of students and staff to examine the impact of the blended learning initiatives ${ }^{16,17,18,19}$. Data collection was by means of questionnaires. Two questionnaires were written, one for the students and one for the staff. The student questionnaire contained a higher proportion of closed questions than the staff questionnaire. The research was considered by a Local Research Ethics Committee (LREC) to ensure the research complied with institutional standards.

The student questionnaire was structured around the identified technologies of podcasting and electronic voting systems. Students were recruited on a voluntary basis. On podcasting, the focus was primarily on the effectiveness of the podcasts in terms of accessibility. The students were asked to specify how long they spent studying with the podcast so that comparisons could be made to the previous traditional two- hour lecture. It was thought relevant to attempt to establish how many times the students listened to the audio file, and where and when they accessed them to establish to how much the students were utilising the flexibility of the initiative. The focus of the questions regarding the electronic voting system was to attempt to quantify how much the students identified the EVS as an effective learning tool.

In the researchers institution modules are taught by teaching teams under the guidance of a module leader. An important facet of the research was to investigate the staff perceptions of the blended learning initiatives. It was identified that the teaching staff would be in an informed position to identify possible challenges and areas for future development. The staff questionnaire contained more open questions focussing on their opinions as to whether they felt that the podcasts and EVS were appropriate learning tools. They were also asked whether they felt that the technologies increased the students' engagement with their learning, and if the inclusion of the learning technologies had an impact on their workload.

As the module ran across the whole academic year, an informal interim evaluation using the electronic voting system was undertaken at the midpoint of the taught sessions as the researchers were mindful that some students could be finding the blended learning initiatives challenging to 
engage with. It was recognised that this could have the effect of prejudicing their opportunities for success across the academic year.

\section{Results}

\section{Interim Student Evaluation}

The interim student evaluation was performed using five MCQs and the EVS, see table 1 below. Due to the aim of the interim evaluation the response rate was not specifically recorded.

\begin{tabular}{|l|l|l|l|l|}
\hline Question & $\begin{array}{l}\text { Agree } \\
\text { strongly }\end{array}$ & Agree & Disagree & $\begin{array}{l}\text { Disagree } \\
\text { strongly }\end{array}$ \\
\hline $\begin{array}{l}\text { I have found the audio files a good way } \\
\text { to learn }\end{array}$ & 53.2 & 12.9 & 8.1 & 3.2 \\
\hline $\begin{array}{l}\text { I would rather have the Monday morning } \\
\text { lecture than the audio file }\end{array}$ & 3.2 & 8.1 & 16.1 & 56.5 \\
\hline $\begin{array}{l}\text { I feel that the small group sessions help } \\
\text { to reinforce my learning }\end{array}$ & 46.8 & 25.8 & 1.6 & 1.6 \\
\hline $\begin{array}{l}\text { I would rather have 2 lectures than the } \\
\text { current pattern of teaching }\end{array}$ & 6.5 & 4.8 & 12.9 & 59.7 \\
\hline $\begin{array}{l}\text { I think the module should continue in its } \\
\text { current format }\end{array}$ & 56.5 & 21.0 & 3.2 & \\
\hline
\end{tabular}

Table 1. Results of interim student survey.

The interim student evaluation revealed that given the option to return to a traditional method of delivery $77.5 \%$ of students either "agreed" or "strongly agreed" that the module should continue to run in its blended format.

\section{Student end of module evaluation}

A high response rate was acheived from the student group with $75 \%(n=77)$ choosing to complete a questionnaire. A total of $65 \%$ of the group started the programme straight from school and of these $68 \%$ rated their information and communication technology (ICT) skills as very good or good. A comparative $61 \%$ of the mature students rated their ICT skills similarly (see figure 2 ).

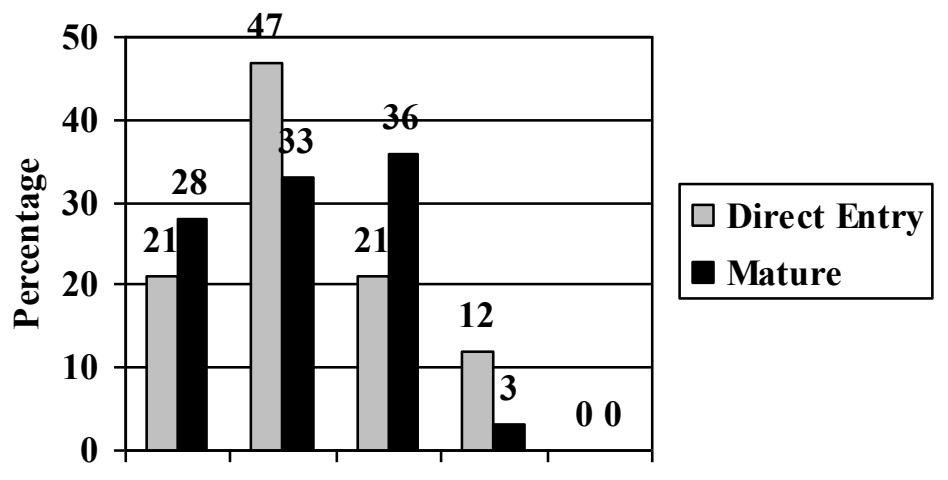


Encouragingly $97 \%$ of the direct entry group and $92 \%$ of the mature students accessed the podcasts (audio files) regularly. There were no differences in how easy the two groups found accessing the podcasts $(97 \%$ easy or fairly easy) or where the two groups accessed the information $(95-97 \%$ at home). Approximately $50 \%$ of each group stated that they downloaded the files to an MP3 player or equivalant.

When the students accessed the podcasts was also remarkably similar, with $66 \%$ of the direct entry and $65 \%$ of the mature students using the materials between Friday and Sunday. Similarly $39 \%$ of the direct entry compared to $35 \%$ of the mature students studied with the materials outside conventional working hours (after $5 \mathrm{pm}$ ). An almost identical 94\% direct entry and $95 \%$ mature students accessed the podcast either only once or twice leaving only $5-6 \%$ of the whole student group accessing the information more than twice.

The average length of time spent studying with the podcasts was 4 hours for the direct entry group and 3.5 hours for the mature students although there was a much wider variation in the direct entry group with one hour being the minimum and twelve hours being the maximum compared to two and six hours respectively for the mature group (See figure 3).

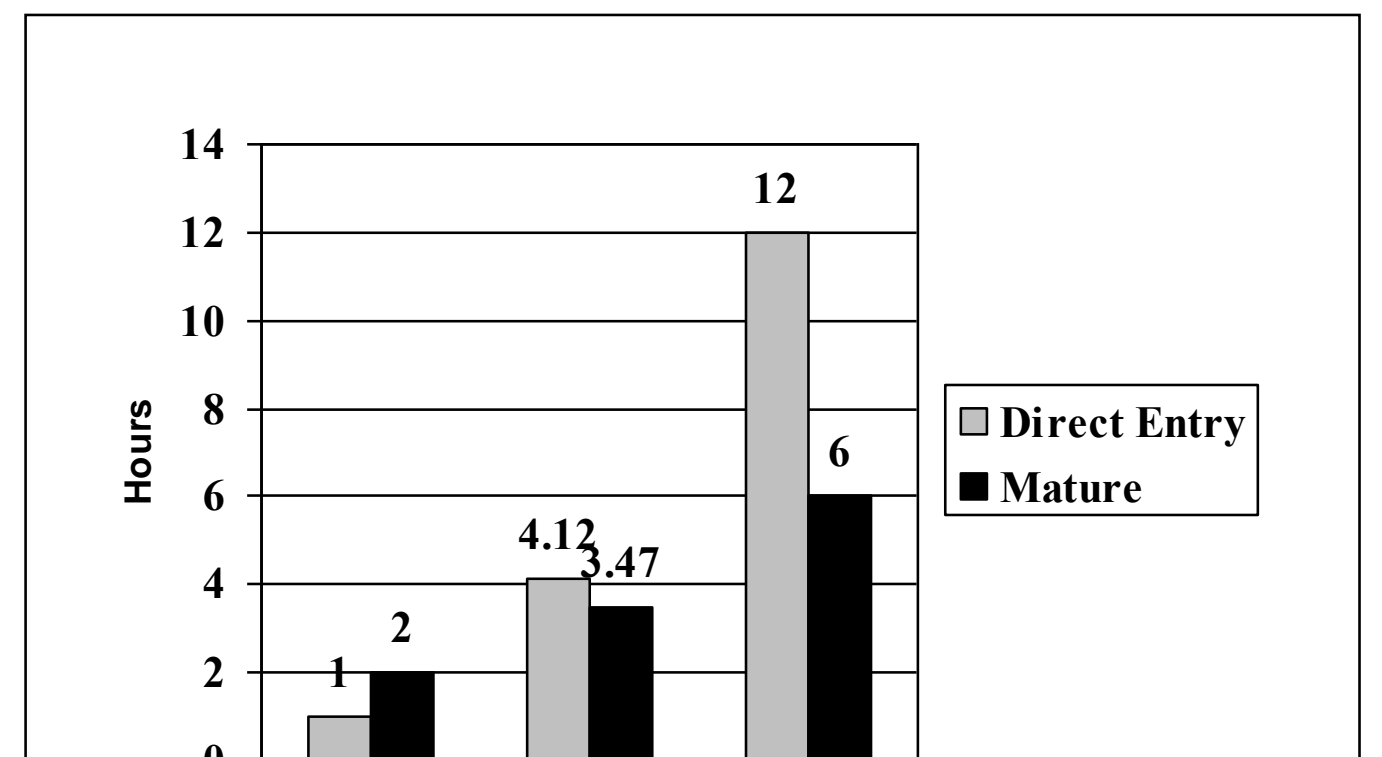


A slightly higher proprotion of the direct entry group (24\%) stated that they would have preferred the traditional two hour lecture to the podcast compared to the mature students $(16 \%)$, with a majority of $76-84 \%$ expressing satisfaction with the podcasts as a method of teaching.

The use of the EVS during the module proved to be very well received by both groups of students. It was easy to use ( $97 \%$ direct entry and $100 \%$ mature students), perceived as helping the students to learn (88\% direct entry and $97 \%$ mature) and useful for exam preparation ( $88 \%$ direct entry and $85 \%$ mature students).

\section{Staff end of module evaluation}

All of the teaching team chose to complete a questionnaire $(n=4)$. The staff identified that the podcasts were influential in encouraging all of the students to be more engaged and self directed in their learning. All of the teaching team had directly seen the students enjoyment and interaction with the EVS and had used the module to learn how to use it themselves. The teaching team were in no doubt that the blended learning technologies had increased the students engagement with their learning although there was a suggestion from two members of staff that at some stages they had had to spend a significant time in preparing for the teaching sessions.

\section{Discussion}

\section{Interim Student Evaluation}

Based on the result of the interim evaluation, the researchers continued to use the learning technologies in the module delivery. The strongest agreement for the pattern of delivery was for the use of small group sessions. This reinforces the researchers beliefs that small group work enhances learning, and that with cohorts of over 100 students delivery patterns should be sufficiently adaptable so that small group work does not become lost. 


\section{Student end of module evaluation}

Regarding access to the podcasts, it had initially been thought that more of the mature students would access the materials out of working hours than the direct entry students although this has not proved to be the case. A common perception that the younger age group would be spending more of the evening socialising than the older age group has not been reinforced. An alternative explanation is that the mature students have more family or work commitments during the evenings and so are not free to study ${ }^{1}$. Only $5-6 \%$ of the whole student group accessed the information more than twice. The researchers were disappointed with this statistic as it was thought the the continuous availabilty of the podcast compared to a lecture was a significant advantage. It was possible that the timing of the evaluation was significant because it was conducted towards the end of the module but before the recognised time for exam preparation and revision. It was thought that perhaps more students would revisit the podcasts as part of their revision activities. Informally, students related that the podcast were very useful for revision purposes, but no actual data collection was conducted to verify this point.

Although there are no significant differences between the average length of time studying between the two groups, the statistics as a whole are taken as an encouraging sign of the students taking responsibility for the management of their own learning ${ }^{6}$. The podcasts were designed to take the place of a two hour traditional lecture so it can be seen that the majority of the students spent more time studying with the new design than they would have if no changes to delivery had been made.

Approximately $50 \%$ of each group stated that they downloaded the files to an MP3 player or equivalant (such as a mobile phone). This was an interesting statistic as it illustrated that the mobile technology is utilised equally among the two groups of students ${ }^{14}$. There was no requirement on the students to download materials to mobile devices, and had this been the case the additional financial implications to the students would have had to be considered. The institution where the study was conducted has extensive computer facilities, although only $3 \%$ of students indicated that they accessed the materials from the university, the overwhelming majority chosing to study with the materials at home ${ }^{15}$. The authors believe that the results are in concordance with the literature regarding the increased flexibility afforded by podcasting compared to traditional delivery methods ${ }^{2,4,5,6}$. 
When asked to comment on the use of podcasts, $65 \%$ of the students used the opportunity. Seven students commented on the length of time taken to study with the podcast of which four were direct entry. This information will be used with future cohorts to inform students on the reality of using podcasts for studying ${ }^{12}$. Of the comments that were not in favour of podcasts all four cited the lack of opportunity to ask questions. The researchers feel that this issue can be addressed through the small group activities in future years with inclusion of a specified time for questions. Alternatively, a specific discussion forum could be set up on the MLE. Over $30 \%$ of the respondents provided additional comments $(n=23)$, the majority of which were positive. Identified themes were the ability to pause the recording, the knowledge that information had not been missed and the benefits of being able to use them in self-study. Two respondents requested a lecture in addition to the podcast. The remaining comments were not specific to the questions asked, and have not been included.

As with the comments on the podcast a high proportion (41\%) of the students used the opportunity to comment on the use of the EVS with $83 \%$ of the comments being enthusiastic ${ }^{10,11}$. The remaining $17 \%(n=7)$ included comments on the need for hard copies of the correct answers and discussion or wanting the questions, images and answers to be put on the MLE (which was done for revision purposes). The positive comments are revealing; examples include having the opportunity to learn from ones mistakes while not being embarrassed at getting the wrong answer as the system is anonymous, such as the quote 'so you don't feel stupid when you get one wrong and you lie and say you got it right'. Other comments included words such as 'interesting' 'fun' and 'different'. Many of the students commented that its use helped their learning such as the comment let me know my weaknesses and helped me to learn what I needed to look up'.

\section{Staff end of module evaluation}

Staff were very positive in their comments on the module delivery method ${ }^{3,9,11}$, illustrated by the following comments:

"It allows flexibility and directs the students to a more self directed approach"; "Increased interest and engagement in the subject"; "There is an element of excitement and interest"; "It was an interesting experience teaching on this module". 
Only one member of the teaching team had experienced students approaching them for help with downloading the podcast at any time during the module. From the discussion site of the MLE it was observed that there was a large amount of student peer support when any difficulties were encountered $^{7,8}$.

\section{Conclusion}

On the findings from the questionnaires, the researchers concluded that the learning technologies did not create barriers for either student group, and that students' engagement with their learning and level of classroom interactivity were both increased when compared with the previous traditional delivery format. The researchers are confident that the described combination of teaching delivery methods are a successful way of allowing small group work to continues with large cohorts. The benefits of the revised teaching pattern for the students are seen to be increased flexibility in when and where they study; the small groups enabled increased opportunities for dialogue with teaching staff when compared to large group lectures. The use of the EVS did increase classroom interactivity and the instant formative feedback was of benefit to students and staff alike.

\section{Acknowledgements}

The researchers acknowledge the support and encouragement of both the teaching team and the student cohort. The technical support available within the university was invaluable particularly in the early days of module delivery.

\section{References}

1. Prensky M. Digital Natives, Digital Immigrants Part 1. On the horizon 2001; 9 (5): 2-6.

2. Campbell G. There's something in the air: Podcasting in education EDUCAUSE review 2005; 40(6): $32-47$

3. Prensky M. Listen to the natives. Learning in the digital age 2005; 63(4): 8-13.

4. Molina PG. and the 2006 EDUCAUSE Evolving Technologies Committee. Pioneering new Territory and Technologies EDUCAUSE review 2006; 41(5): 112-35 
5. Laurillard D. Rethinking university teaching: A framework for the effective use of educational technology. London: Routledge; 1993.

6. Brown S, Race P. Lecturing - a practical guide. London: Kogan Page; 2002.

7. Cairncross, F. The death of distance: how the communications revolution will change our lives. Boston: Harvard Business School Press; 1997.

8. Graetz K, Goliber MJ. Designing collaborative learning places: psychological foundations and new frontiers. New Directions for Teaching and Learning 2002; 92; $13-22$.

9. University of Hertfordshire Blended Learning Unit. Available at:

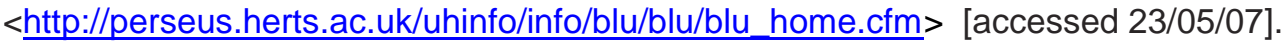

10. Kennedy GE, Cutts QI. The association between students' use of an electronic voting system and their learning outcomes. Journal of computer assisted learning 2005; 21: 260-268.

11. Draper SW, Brown MI. Increasing interactivity in lectures using an electronic voting system. Journal of computer assisted learning 2004; 20: 81-94.

12. Motteram G. Blended education and the transformation of teachers: a long term case study in postgraduate UK Higher Education. British Journal of Educational Technology 2006; 37(1): 17-30.

13. Laing C, Wootton A, Irons A. iPod! uLearn? In:

Mendez Vilas, Solano Martin A, Mesa Gonzalez J, Mesa Gonzalez JA. (Eds). Current developments in technology-assisted education vol. 1. Badajoz (Spain): FORMATEX; 2006: 514518.

14. Educause. 7 things you should know about ...podcasting. Available at: $<$ http://www.educause.edu/ir/library/pdf/ELI7003.pdff; 2005 [accessed 28/05/07].

15. Philip, D. The Knowledge Building paradigm: A model of learning for Net Generation students. Available at: $<$ http://www.innovateonline.info/index.php?view=article\&id=368>; 2007 [accessed 31/05/07].

16. Robson, C. Real world research. Oxford: Blackwell; 1993.

17. Polit DF, Hungler BP. Essentials of nursing research. Philadelphia: Lippincott; 1997.

18. Walton G, Childs S, Blenkinsopp E. Using mobile technologies to give health students access to learning resources in the UK community setting", Health Information and Libraries Journal 2005; 22(2): 51-65. 
19. Ausburn, LJ. Course Design Elements Most Valued by Adult Learners in Blended Online Education Environments: An American Perspective. Educational Media International 2004; 41(4): 327-337. 